\title{
Distinct Dose-Dependent Cortical Neuronal Migration and Neurite Extension Defects in Lis1 and Ndel1 Mutant Mice
}

\author{
Yong Ha Youn, ${ }^{1}$ Tiziano Pramparo, ${ }^{1}$ Shinji Hirotsune, ${ }^{2}$ and Anthony Wynshaw-Boris ${ }^{1}$ \\ ${ }^{1}$ Department of Pediatrics, Institute for Human Genetics, University of California, San Francisco School of Medicine, San Francisco, California 94143-0794, \\ and ${ }^{2}$ Department of Genetic Disease Research, Osaka City University Graduate School of Medicine, Osaka 545-8586, Japan
}

\begin{abstract}
Haploinsufficiency of LIS1 results in lissencephaly, a human neuronal migration disorder. LIS1 is a microtubule- (MT) and centrosome[microtubule organizing center (MTOC)] associated protein that regulates nucleokinesis via the regulation of dynein motor function and localization. NDEL1 (NudE isoform, NudE like) interacts with LIS1/dynein complex, and is phosphorylated by CDK5/P35. Previous reports using siRNA-mediated knock-down demonstrated similar critical roles for LIS1 and NDEL1 during neuronal migration, but neuronal migration has not been studied in genetic mutants for Lis 1 and Ndell where protein levels are uniform in all cells. Brains from mice with complete loss of Lis 1 and Ndel1 displayed severe cortical layering and hippocampal defects, but Lis1 mutants had more severe defects. Neuronal migration speed was reduced and neurite lengths were elongated in proportion to the reduction of LIS1 and NDEL1 protein levels in embryonic day 14.5 mutant cortical slices compared to wild type, using two-photon confocal time lapse videomicroscopy. Additionally, mice with $35 \%$ of wild-type NDEL1 levels displayed diverse branched migration modes with multiple leading processes, suggesting defects in adhesion and/or polarity. Complete loss of Lisl or Ndell resulted in the total inhibition of nuclear movement in cortical slice assays, and in neurosphere assays, the percentage of migrating neurons with correctly polarized MTOC location was significantly reduced while nuclear-centrosomal distance was extended. Neurite lengths were increased after complete loss Ndel1 but reduced after complete loss of Lis1. Thus, Lis1 and Ndel1 are essential for normal cortical neuronal migration, neurite outgrowth, and function of the MTOC in a dose-dependent manner.
\end{abstract}

\section{Introduction}

Neuronal migration is a highly ordered process that organizes and integrates the positioning of neurons of the neocortex during mammalian nervous system development. Most cortical projection neurons originate from the proliferative ventricular zone (VZ) and these postmitotic cells migrate radially into their final destination in the cortical plate (CP) to form a distinct six-layered laminar cortex in an inside-out manner (Gupta et al., 2002; Nadarajah and Parnavelas, 2002; Ayala et al., 2007). Most GABAergic interneurons originate from the medial and lateral ganglionic eminence (MGE and LGE) of the ventral telencephalon and migrate tangentially to the neocortex to integrate with the projection neurons. In the course of this integration, both types of neural precursors also migrate in a ventricular zone (VZ)-directed pattern to coordinate movements of principle cells and interneurons before they migrate to the cortical plate (Nadarajah and Parnavelas, 2002).

Received Sept. 17, 2009; accepted 0ct. 30, 2009.

This work was supported by grants from the National Institutes of Health (NS041310 and HD047380) to A.W.-B. We thank Lana Bogdanova and Donna Holland for animal handling, Jeehee Hong for technical assistance, as well as Albee Messing and Andrew McMahon for mice. We especially thank Brendan Brinkman for technical expertise and support at the University of California, San Diego Neuroscience Microscopy Shared Facility (P30 NS047101).

Correspondence should be addressed to Anthony Wynshaw-Boris, Department of Pediatrics, Institute for Human Genetics, University of California, San Francisco School of Medicine, 513 Parnassus Avenue, HSE901F, San Francisco, CA 94143-0794. E-mail: WynshawBorisT@peds.ucsf.edu.

DOI:10.1523/JNEUROSCI.4630-09.2009

Copyright $\odot 2009$ Society for Neuroscience 0270-6474/09/2915520-11\$15.00/0
Thus, there are three different directional movement patterns of migrating neuronal progenitors: (1) radial, (2) tangential, and (3) VZ-directed migration. These migration patterns of postmitotic neurons require major cytoarchitectural changes of the microtubule (MT) cytoskeleton (Schaar and McConnell, 2005).

Important insights have come from the study of genes responsible for human neuronal migration defects, such as type I lissencephaly. The first gene cloned that was mutated in lissencephaly was LIS1, encoded by PAFAH1B1 (Reiner et al., 1993; LoNigro et al., 1997). Reduced doses of Lis1 in the mouse result in a disorganization of both projection neurons and interneurons (Hirotsune et al., 1998; Fleck et al., 2000; McManus et al., 2004; Nasrallah et al., 2006). LIS1 is known to function as a MT and MTOC-associated protein that regulates nucleokinesis along MTs via the regulation of dynein motor function (for review, see Gupta et al., 2002; Vallee and Tsai, 2006). For example, cerebellar granule cells from Lis $1^{+/ k o}$ mouse mutants display migration defects such as slowed migration and extension of the distance between the nucleus and centrosome (Hirotsune et al., 1998; Tanaka et al., 2004). LIS1 is part of a complex conserved from yeast to mammals that regulates dynein motor function (for review, see Gupta et al., 2002; Vallee and Tsai, 2006). Another component of the LIS1 complex is NDEL1 (NudE isoform, NudE-like), which directly binds LIS1 and dynein (Niethammer et al., 2000; Sasaki et al., 2000). NDEL1 is also required for neuronal migration (Shu et al., 2004; Sasaki et al., 2005) and is involved in targeting dynein to the plus end of microtubules via interaction with LIS1/dynein complex (Shu et al., 2004; Li et al., 2005), recruiting katanin (Toyo-Oka et al., 
2005), and is phosphorylated by both Cdc2/Cdk5 and Aurora A kinase (Niethammer et al., 2000; Sasaki et al., 2000; Mori et al., 2007, 2009). LIS1 and NDEL1 together are responsible for the transport of dynein to the cortex of the cell (Yamada et al., 2008).

Recently, several reports have demonstrated that LIS1 and NDEL1 are essential for neuronal positioning and nuclear migration using siRNA-mediated knock-down (Shu et al., 2004; Tsai et al., 2005). Here, we have investigated neuronal migration in genetic mutants of Lis1 and Ndell using time lapse two-photon videomicroscopy. We describe significantly impaired neuronal migration with elongation of neurites in LIS1-deficient neural precursors $\left(L i s 1^{+/ k o}\right.$ and $\left.L i s 1^{h c / k o}\right)$ and diverse branched migration modes in NDEL1-deficient $\left(N d e 1^{h c / k o}\right)$ mice due to frequent changes of the direction of movement and the extension of multiple leading processes. Using an in vitro neurosphere assay, we confirmed these migration defects and were able to examine cell biological properties of these cells such as neurite length and the position of the MTOC in moving cells in Lis1 and Ndell mutant neural stem cells. The proportion of postmitotic migrating neurons with correctly polarized MTOC location was significantly reduced and the nuclear-centrosomal $(\mathrm{N}-\mathrm{C})$ distance was greatly extended in neurons that were completely missing either Lis 1 or Ndel1 in vitro. Complete loss of Lis1 or Ndel1 using hGFAP- and Tamoxifen-Cre induced Lisl and Ndell conditional knock-out mice resulted in the total inhibition of movement and impaired formation of leading processes in the developing neocortex.

\section{Materials and Methods}

Mice. Lis1 null [Lis ${ }^{k o}$, also denoted Pafah1b1-neo (Hirotsune et al., 1998)] and hypomorphic conditional knock-out [Lis $1^{h c}$, also denoted Pafah1b1-loxP (Hirotsune et al., 1998)] alleles were used. Ndel1-null $\left(\mathrm{Ndell}^{k o}\right)$ and conditional $\left(\mathrm{Ndell}^{h c}\right)$ alleles were used as previously described (Sasaki et al., 2005). To produce mice with complete loss of Lis 1 or Ndel1 in the cortex, homozygous conditional mutants for each gene were mated to the $h G F A P$-Cre line (Zhuo et al., 2001). To temporally knock out either Lis1 or Ndell, we used the tamoxifen-inducible Cre-ER line (Hayashi and McMahon, 2004) (Jackson Laboratory strain B6.Cg-Tg (cre/Esr1) $5 \mathrm{Amc} / \mathrm{J}$ ), as we previously used for the analysis of Lis1 mutants (Yingling et al., 2008).

Histology and immunohistochemistry on whole brains. Embryonic brains were fixed in $4 \%$ paraformaldehyde (PFA) in PBS, soaked in 30\% sucrose overnight, transferred into OCT compound (Sakura), frozen, and coronally sectioned ( $20 \mu \mathrm{m}$ thickness). Frozen sections stained with cresyl violet (Nissl) were or immunostained with primary antibodies Cux1 (1:100; Santa Cruz Biotechnology) and FoxP1 (1:100; ABCAM), after dilution in 5\% normal goat serum, $0.5 \%$ Triton X-100 in PBS. Secondary antibodies used were the following: rhodamine-conjugated anti-rabbit IgG and FITC-conjugated anti mouse IgG (1:100; Jackson ImmunoResearch Lab). DAPI (Invitrogen) was used were for nuclear staining. Images were captured using confocal microscopy (Nikon).

Organotypic cortical slice culture. We modified a previously described protocol to examine neuronal migration in cortical slices (Nadarajah et al., 2001, 2003). Whole brains were isolated from embryos at day 14.5 of gestation (E14.5) and sectioned coronally in $350 \mu \mathrm{m}$ slices by a tissue slicer. The sectioned cortical slices were stained by Oregon-Green BAPTA-1 488 AM (Invitrogen) and $0.003 \%$ pluronic acid (Invitrogen) for $1 \mathrm{~h}$ at $37^{\circ} \mathrm{C}$ and washed twice with PBS. The stained cortical slices were transferred onto $35 \mathrm{~mm}$ culture dishes and covered by neutralized collagen. The collagen matrix was allowed to solidify for 20-30 min and covered DMEM/F12 medium containing $1 \times \mathrm{N}_{2}$ supplement (Invitrogen). Live images were captured by an Olympus two photon confocal microscope equipped with the Olympus Fluoview software program, and the time lapse images were analyzed by ImagePro (Schmid et al., 2004).

Neurosphere formation and attachment. We modified previously described protocols (Engele and Bohn, 1992; Reynolds and Weiss, 1996; Calaora et al., 2001) to perform in vitro analysis using neurospheres.
Cerebral cortices were dissected and isolated from E14.5 mouse embryos, incubated in $0.1 \mathrm{mg} / \mathrm{ml}$ papain solution for $15 \mathrm{~min}$ at $37^{\circ} \mathrm{C}$, trypsin inhibitor for $10 \mathrm{~min}$ at room temperature, and ultimately triturated using a fire-polished Pasteur pipette. The cells were filtered, added to six-well plates containing $\mathrm{N}_{2}$ supplement with DMEM, $10 \mathrm{ng} / \mathrm{ml}$ human recombinant epidermal growth factor, and $10 \mathrm{ng} / \mathrm{ml}$ basic fibroblast growth factor, then incubated at $37^{\circ} \mathrm{C}$ in $95 \%$ air and $5 \% \mathrm{CO}_{2}$ in a humidified chamber. Fresh growth factors were added every other day, allowing cells to grow as floating neurospheres. For the in vitro migration assay, each neurosphere was carefully transferred onto glass coverslips coated with laminin, and incubated in the same culture conditions as mentioned above. Two days later, many migrating neuronal progenitor cells moved radially out from the attached neurosphere. Migration from the neurosphere cultures was determined by measuring the length of each neural precursor cell outgrowth from the attached neurosphere. The length of outgrowth was measured from the total culture area using ImageJ software program.

Immunohistochemistry. Cultured neural stem cells on coverslips were gently washed with PBS twice and fixed with $4 \%$ paraformaldehyde in PBS for $1 \mathrm{~h}$. Fixed slides were incubated in blocking buffer (5\% normal goat serum, $0.5 \%$ Triton X-100 in PBS) for $30 \mathrm{~min}$ at room temperature, the primary antibodies such as monoclonal anti-mouse nestin (1:100; Millipore Bioscience Research Reagents) and $\gamma$-tubulin (1:100; Sigma), polyclonal anti-rabbit GFAP (1:100; Dako), and pericentrin (1:5000; Covance) were incubated overnight at $4^{\circ} \mathrm{C}$. After washing, secondary antibodies (anti-mouse FITC or anti-rabbit Rhodamine in 1:100 dilution in blocking buffer) were incubated for $1 \mathrm{~h}$ at room temperature in the dark. After washing three times with PBS, the slides were carefully mounted with mounting solution containing DAPI and anti-fading reagent (Invitrogen). To analyze the polarity of the centrosome of moving cells, the orientation of the centrosome preceding the nucleus was measured based upon the frontier line of the outgrowth area, rather than the line of the wound in wound-healing studies of fibroblasts in culture (EtienneManneville and Hall, 2001). N-C distance was measured between centrosome and nucleus in single neurons cultured from neural spheres as described previously (Tanaka et al., 2004).

\section{Results \\ Disorganization of cortical layer formation and hippocampal defects in Lis1 and Ndel1 genetic mutant mice}

To examine the roles of Lis1 and Ndel1 during neocortical formation, we used the $h G F A P$-Cre transgenic mouse to completely inactivate Lis1 and Ndel1 conditional alleles and eliminate LIS1 and NDEL1 protein (Zhuo et al., 2001). As we previously demonstrated (Yingling et al., 2008), Lis ${ }^{+/ h c}$; $h$ GFAP mice formed a fairly normal neocortex and displayed some splitting of the hippocampal pyramidal cell layer (Fig. $1 A, C$ ), similar to $L i s 1^{+/ k o}$ mice (Hirotsune et al., 1998; Gambello et al., 2003), while Lis $1^{\text {hc/hc }}$; $h$ GFAP mice displayed a complete absence of the hippocampus and a significantly thinner cortex (Fig. $1 B, D$ ), and survived only a few days after birth, probably due to severe defects of brain development. To further analyze cortical layer formation, we used Cux1 and FoxP1 as laminar markers for layers II/III and III/IV, respectively. Cux1- and FoxP1-positive cells were normally placed in specific layers in $L i s 1^{+/ h c} ; h G F A P-C r e$ brains (Fig. $1 E-H)$. However, Cux1-positive cells were rarely found in upper layer of the cortex and FoxP1-positive cells were significantly reduced and scattered in the middle of the cortex of $\operatorname{Lis} 1^{h c / h c}$; hGFAP-Cre brains (Fig. $1 I-L)$. Ndell ${ }^{h c / h c}$; hGFAP-Cre mice survived to weaning. The hippocampus formed in these mice, but the pyramidal and granule cells were disorganized (Fig. 1N,P), and the cortex was thinner compared with the normal hippocampus and cortex in the $N d e l 1^{+/ h c}$; hGFAP-Cre mice (Fig. $1 \mathrm{M}, \mathrm{O}$ ). The number of Cux1- and FoxP1-positive cells was reduced in both layer II/III and III/IV in Ndell ${ }^{h c / h c}$; $h$ GFAP-Cre brains (Fig. $1 U-X)$ compared to $\mathrm{Ndel1}^{+/ h c}$; hGFAP-Cre brains (Fig. 1Q-T), 

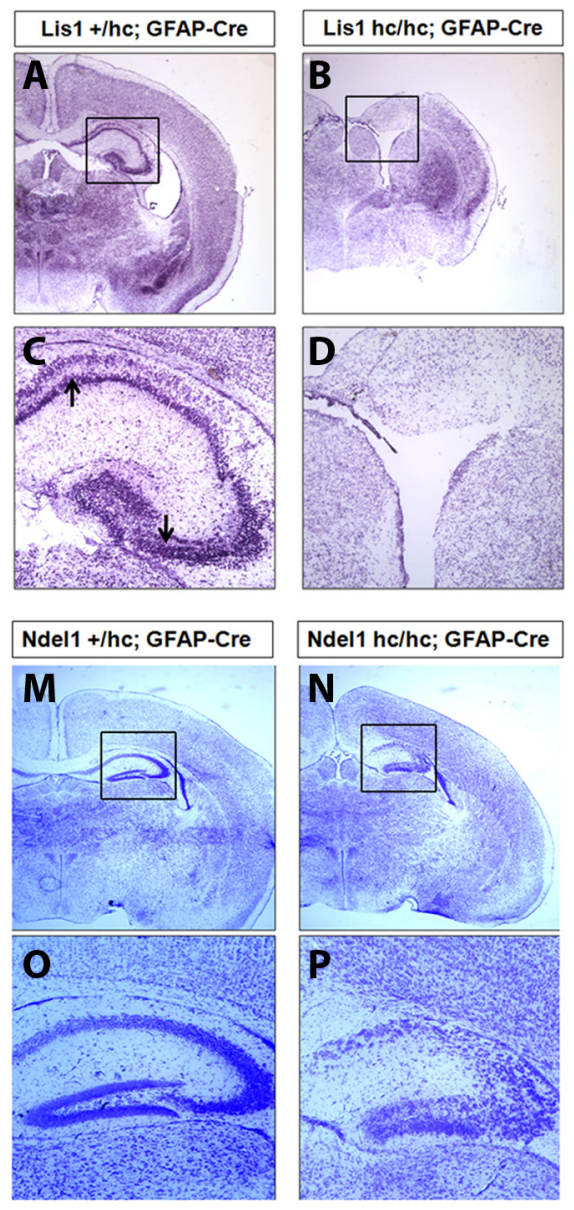

Lis1 +/hc; GFAP-Cre
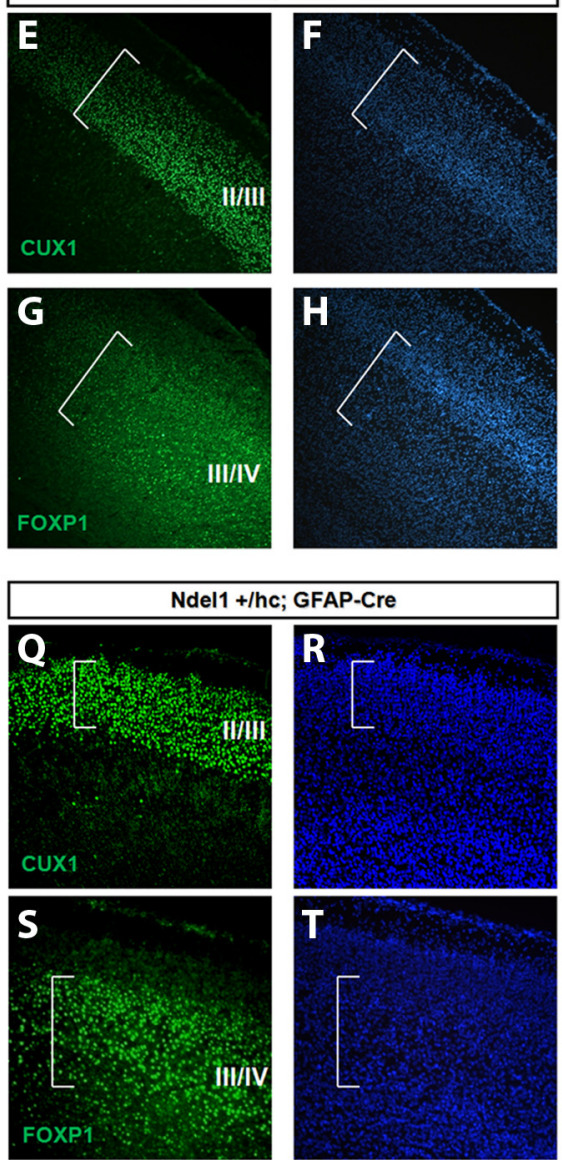
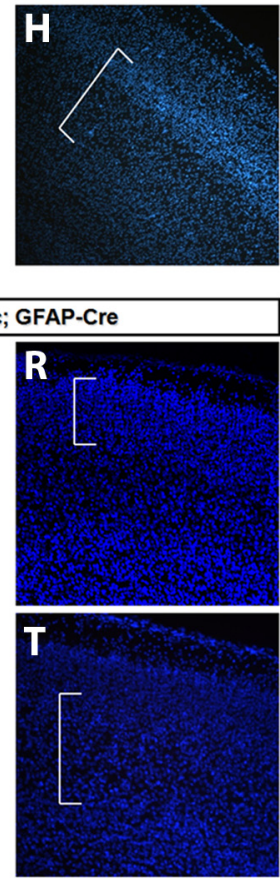
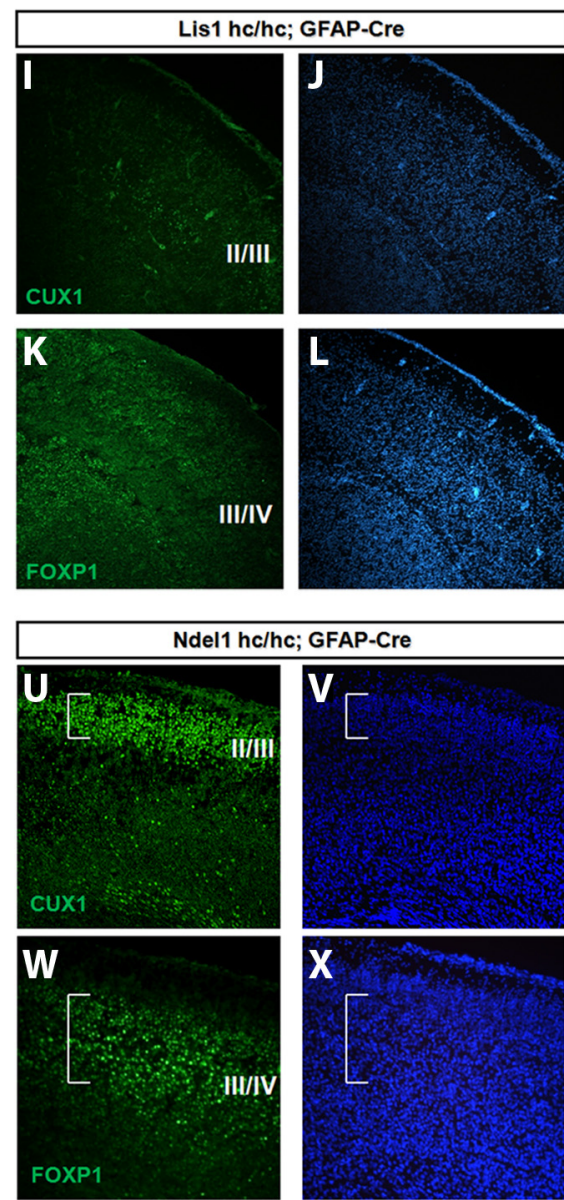
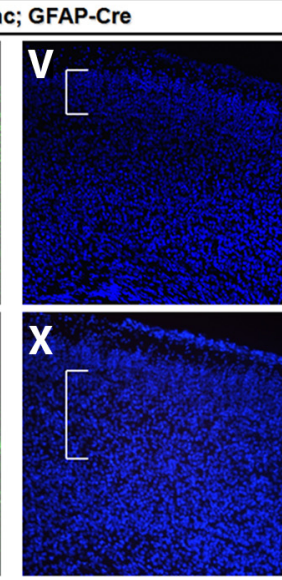

Figure 1. Cortical and hippocampal defects in $L i s 1$ and $N$ del 1 genetic mutant mice after cresyl violet staining $(\boldsymbol{A}-\boldsymbol{D}, \boldsymbol{M}-\boldsymbol{P})$. Arrows indicate some splitting of the hippocampal pyramidal cell layer. $\boldsymbol{E}-\boldsymbol{L}, \mathbf{Q}-\boldsymbol{X}, \mathbf{L}$ Laminar patterning is disrupted in $L i s 1$ and $N$ del 1 mutant cortex. Identical immunostained $(\boldsymbol{E}, \boldsymbol{G}, \boldsymbol{I}, \boldsymbol{K}, \mathbf{Q}, \mathbf{S}, \boldsymbol{U}, \boldsymbol{W})$ and $D A P I(\boldsymbol{F}, \boldsymbol{H}, \boldsymbol{J}, \boldsymbol{L}, \boldsymbol{R}, \boldsymbol{T}, \boldsymbol{V}, \boldsymbol{X}$, respectively) counterstained sections were

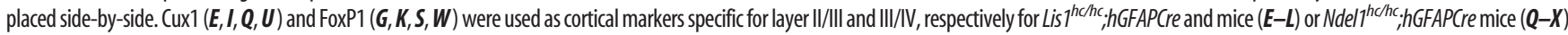
at P5. In the matched immunostained and DAPI stained sections, the brackets indicate the extent of immunostaining to facilitate localization of the pattern of expression to the entire cortex.

but they were appropriately placed. These results demonstrate that complete loss of Lis1 is more severe than the complete loss of Ndell, probably due to some functional redundancy of Ndell and Nde1, but that complete deletion of both Lis1 or Ndel1 caused severe brain defects during development.

\section{Reduced neuronal migration velocity after reduction of Lis 1 in cortical slices}

To elucidate the detailed mechanisms of movement patterns and dynamics during cerebral cortex development in Lis1 genetic mutant mice, we observed the speed of movement and morphology of neuronal precursor cells using time lapse confocal videomicroscopy of embryonic cortical slice cultures labeled with Oregon Green BAPTA-1 AM (Nadarajah et al., 2001). As previously described, we observed three distinct types of movement patterns (radial, tangential and VZ-directed migration) in cortical slices from wild-type embryonic brain (Fig. 2A-C). Many migrating neuronal precursor cells had one leading process (monopolar) in the intermediate zone (IZ) and SVZ (Fig. 2 A; supplemental Movie 1, available at www.jneurosci.org as supplemental material). Neuronal precursor cells in cortical slices from $L i s 1^{+/ k o}$ embryonic brains, with $50 \%$ of wild-type LIS1 protein, moved more slowly compared with wild-type cells and occasionally displayed a multidirectional migration pattern with long and curved leading processes (Fig. $2 D$ ). In cortical slices from Lis $1^{h c / k o}$ mice, with $35 \%$ of wild-type LIS1 protein, most neuronal precursor cells in the IZ did not move, as indicated by a stationary pattern of soma (triangles), and many migrating neurons had a long leading process with occasional branch points (arrows) (Fig. 2F, G; supplemental Movie 2, available at www.jneurosci.org as supplemental material). These results demonstrated that Lis 1 reduction resulted dose-dependent reduction in migration.

\section{Reduced neuronal migration velocity and multidirectional movements with branched migration after reduction of} Ndel1 in cortical slices

We next analyzed the speed of movement and morphology of neuronal precursor cells in embryonic cortical slices from Ndel1 genetic mutant mice, using time lapse confocal videomicroscopy. In slices from $N d e l 1^{h c / k o}$ mice, with $35 \%$ of NDEL1 protein levels, migration speed was also slowed compared to wild-type precursors (Fig. $3 A, B$; supplemental Movie3, available atwww.jneurosci. org as supplemental material). In addition, various abnormal patterns of branching migration were observed (Fig. $3 A, B$ ). To further analyze these abnormal branched patterns of migration in cortical slices from $N d e l 1^{\text {hc/ko }}$ embryos, we outlined all images of single moving cells in IZ as silhouettes in a time-dependent manner, and compared these movements with those in wild-type slices (Fig. $3 A, B$ ). There were various branched and multidirectional movements displayed by cells from $N d e l 1^{h c / k o}$ cortical slices, interspersed with pauses or stationary states, and this pattern was not seen in wild-type slices. The angle of change in the 

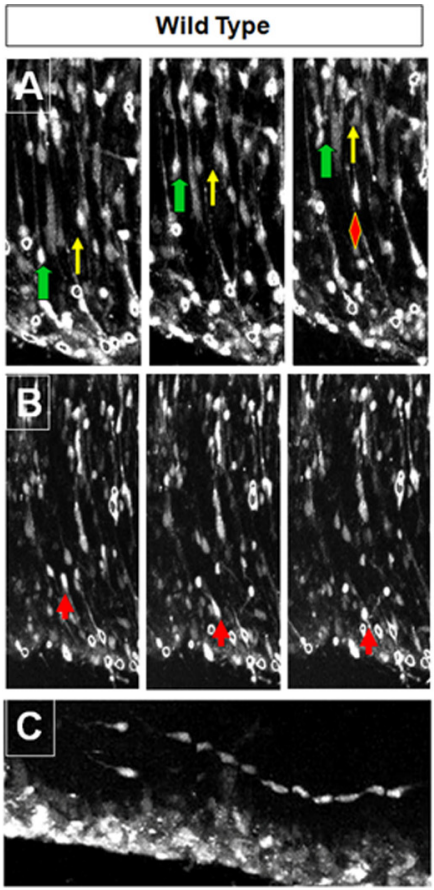

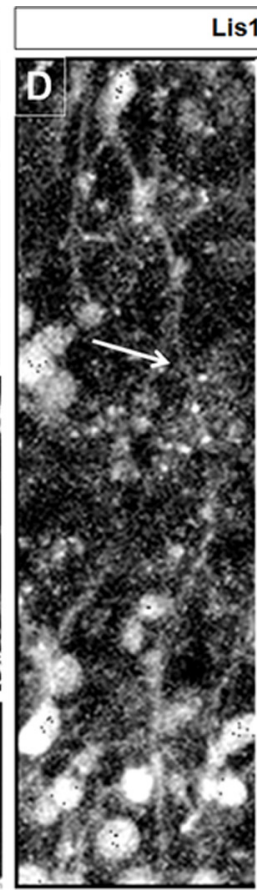

Lis1 +/ko
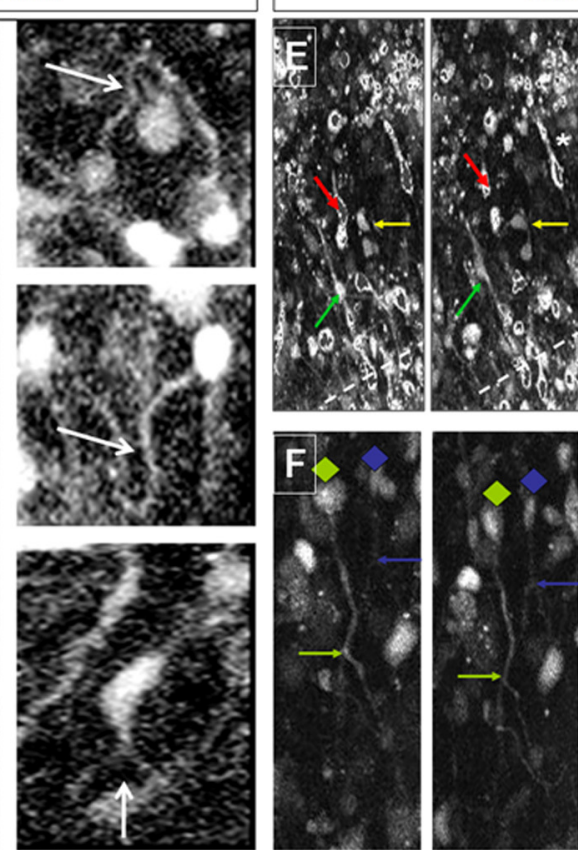

is $1 \mathrm{hc} / \mathrm{ko}$
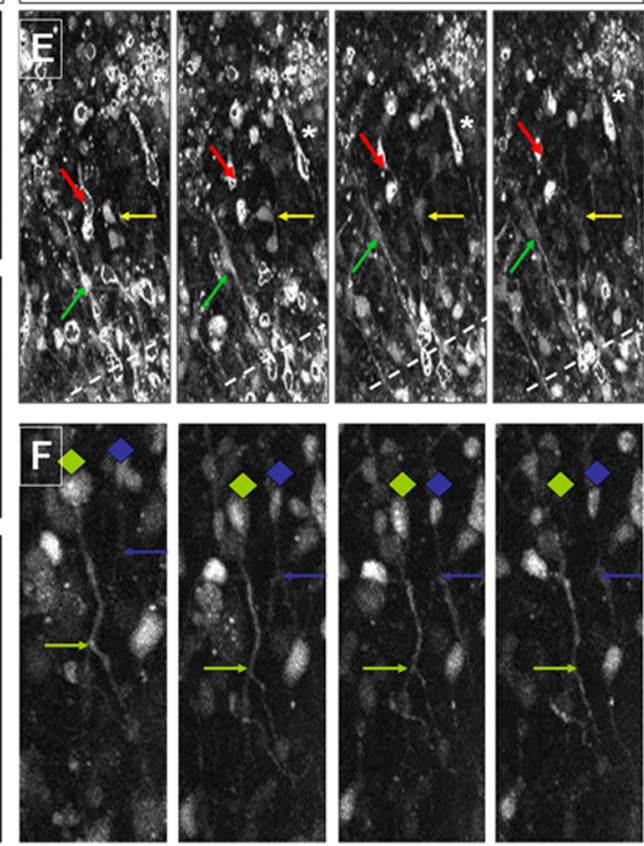

Figure 2. Abnormal and slow neuronal migration of Lis 1 mutant precursor cells in organotypic cortical slice cultures using time lapse confocal videomicroscopy. A-C, Three distinct types of movement patterns (radial, tangential and VZ-directed migration) were observed in cortical slice cultures from wild-type mice at E14.5. The yellow and green arrows indicate radially migrating cells $(\boldsymbol{A})$, and the red arrow a VZ-directed migrating cell $(\boldsymbol{B})$. For tangential migration $(\boldsymbol{C})$, kymography denotes the serial movement patterns. $\boldsymbol{D}$, Unique migration patterns with curled and long leading processes in cortical slices from $L i s 1^{+/ k o}$ mice. $E$, $F$, In cortical slices from $L i s 7^{h / / k o}$ mice, most of the neuronal precursor cells in the $I Z$ did not move and displayed a long leading process. The cell bodies were mostly stationary (triangles). Arrows indicate branch points in leading process.
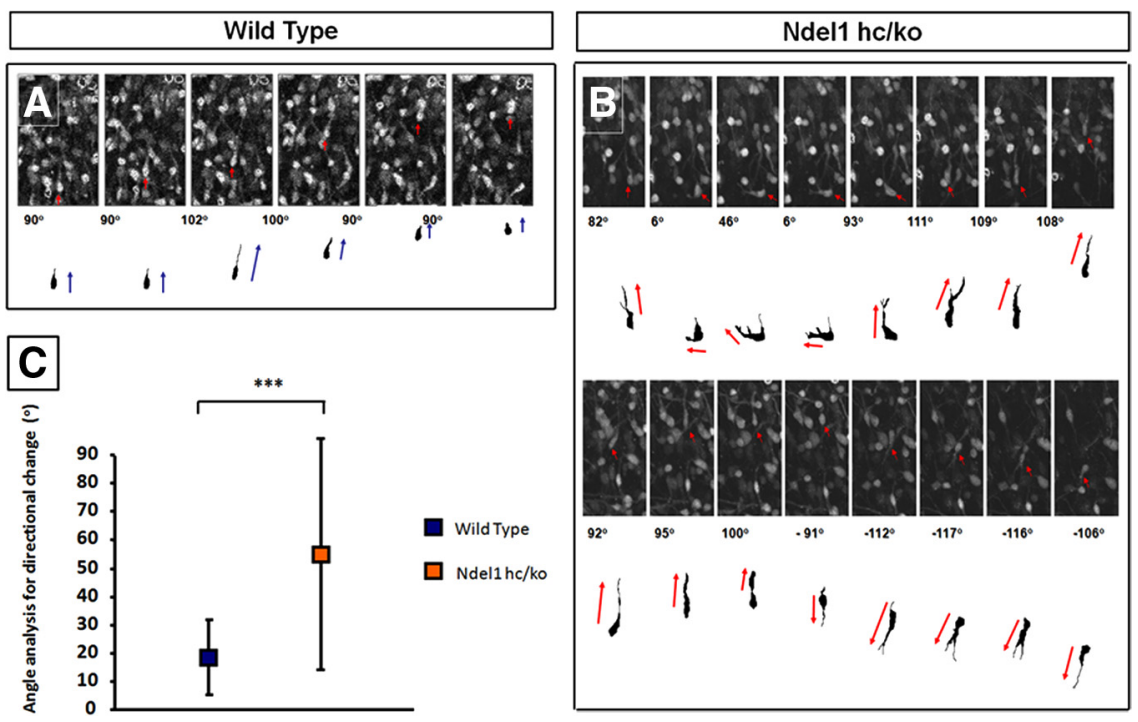$$
\text { : }
$$

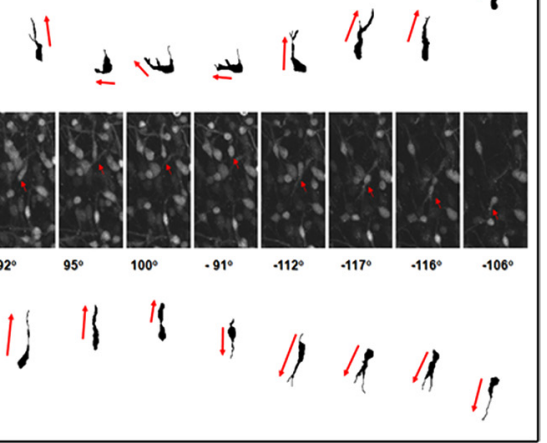

Figure 3. Multidirectional movements, slow migration and increased lengths of leading processes in neural precursors from of Ndel $/ 7^{\text {hc/k }}$ precursor cells in organotypic cortical slice cultures using time lapse confocal videomicroscopy. $A, B$, Images of single moving cell in the IZ at different time points illustrated the boundaries of cell bodies and processes (silhouettes) from each cell in a time-dependent manner. Various branched and multidirectional movements as well as stationary state cells were observed in Ndel $/ 7^{\text {hc/ko }}$ cortical slices. C, The angles of change in moving direction. Migrating cells from wild-type slices moved in a mostly straightforward direction with an average angle of $18.16^{\circ}$. However, the cells in Ndel $7^{\text {hc/ko }}$ slices frequently changed their direction of movement with an average angle of $59.55^{\circ}, p<0.00005$ (Student's $t$ test).

direction of movement was measured from these images in neuronal precursor cells. Migrating cells from wild-type slices moved mostly in a straightforward direction, with an average angle change of $18.16^{\circ}$ (Fig. $3 C$ ). However, cells in Ndel1 ${ }^{\text {hclko }}$ slices changed their direction of movement, with an average angle change of $59.55^{\circ}(p<0.00005$, Fig. $3 C)$. Many moving cells in IZ from Ndell ${ }^{h c / k o}$ slices completely reversed their direction and displayed several leading processes (Fig. 3C). Migration speed was also slowed in slices from Ndel1 ${ }^{h c / k o}$ mice, and various abnormal migration patterns were observed. The most prominent type was an irregular migration pattern with secondary forks and branched processes that frequently changed their direction of movement ("zig-zag" pattern) without apparent radial glial guidance. This zig-zag pattern was not observed in either of the Lis1 mutant cortical slices (data not shown; supplemental Fig. 1, available at www.jneurosci.org as supplemental material).

\section{Absence of migration after complete elimination of \\ Lis 1 and Ndel1}

We next examined the effect of complete loss of Lis1 and Ndel1 using each conditional knock-out and two different Cre transgenic lines: hGFAP-Cre (Zhuo et al., 2001) (also used in Fig. 1) and Cre-ER (Hayashi et al., 2002). hGFAP-Cre is expressed in the radial glial progenitor cells of cortex that eventually give rise to radially migrating cortical neurons in the ventricular zone after E12.5-13.5. To induce acute loss of Lis1 and Ndell protein in the neocortex, we injected pregnant mice ( $L i s 1^{\text {hcl }}$ ${ }_{h c}$;Cre-ER or Ndel1 ${ }^{h c / h c}$;Cre-ER) with tamoxifen to activate Cremediated genetic recombination $24 \mathrm{~h}$ before embryonic dissection, and analyzed the patterns of neuronal migration in 
cortical slice cultures. To illustrate single cell movements, cell boundaries at each time point were traced with different colors, and then all time points were merged. In wild-type slices, the entire series of panels is shown, demonstrating movement of each of the outlined cells (Fig. 4A). Complete loss of Lis1 or Ndel1 using hGFAPCre or Cre-ER resulted in a significant inhibition of neuronal migration in slices from the developing neocortex (Fig. $4 B-F$ ). Neuronal migration in Lis $1^{\text {hc/hc }}$; GFAP-Cre slices was completely inhibited. The cell boundaries at each of the time points were not different compared to the boundaries in the first images and neurons displayed reduced numbers of leading processes and branches (Fig. 4C; supplemental Movie 4, available at www.jneurosci.org as supplemental material). Similarly, migration of Ndel1 ${ }^{\text {hchc }}$; hGFAP-Cre cells was significantly reduced compared to either wildtype (Fig. $4 \mathrm{~A}$ ) or Ndell ${ }^{\text {hc/ko }}$ control cells. Some neuronal precursor cells in Ndel1 ${ }^{\text {hcl }}$ ko; $h$ GFAP-Cre displayed branched migration patterns, but most cells were stationary (Fig. $4 D$; supplemental Movie 5 , available at www.jneurosci.org as supplemental material). Analysis of $L i s 1^{h c h c}$; Cre-ER and Ndel1 ${ }^{h c / h c}$;Cre-ER cortical slices revealed a similar severe reduction in neuronal migration $24 \mathrm{~h}$ after administration of tamoxifen (Fig. $4 E, F$ ). The cell boundaries of each of the time points were not different compared to the boundaries in the first images in Lis ${ }^{h c / h c} ; C r e-E R$ and Ndel1 ${ }^{h c / h c} ; C r e-E R$ slices, demonstrating significant impairment in cell movements after the complete loss of Lis1 and Ndell by two different Cre lines.

\section{Dose-dependent reduced migration velocity and numbers of migrating neurons in Lis1 and Ndel1 mutant cortical slices}

As noted in the previous sections, the velocity of migration was decreased in neural progenitors from cortical slices in $L i s 1^{+/ k o}$, Lis $1^{h c / k o}$ and Ndel ${ }^{h c / k o}$ mice, and in cortical slices from these Lis 1 and Ndel1 partial loss-of-function mutants, the reduced speed was evident in all three directional migration patterns (Fig. 5A$C$ ), while in complete loss-of-function mutants, there was an absence of movement (Fig. 4). In radial migration, the migration speed of moving wild-type neuronal progenitors was $61.59 \pm$ $17.59 \mu \mathrm{m} / \mathrm{h}$. In moving Lis ${ }^{+/ k o}$ and Lis $1^{\text {hckoo }}$ neuronal progenitors, with 50 and $35 \%$ of LIS1 protein, the average speeds were reduced to $36.11 \pm 3.97$ and $16.4 \pm 6.09 \mu \mathrm{m} / \mathrm{h}$, respectively, a reduction to 54 and $30 \%$ of wild-type speeds. The migration speed of moving Ndell1 $1^{\text {hc/ko }}$ neuronal progenitors was $35.41 \pm$ $14.49 \mu \mathrm{m} / \mathrm{h}, 58 \%$ of wild-type speeds. Migration speeds were similarly reduced in Lisl and Ndel1 mutants migrating in tangential and VZ directions (Fig. 5B,C). In wild-type cortical slices, migration velocities were $65.78 \pm 18.09$ and $61.16 \pm 16.11 \mu \mathrm{m} / \mathrm{h}$
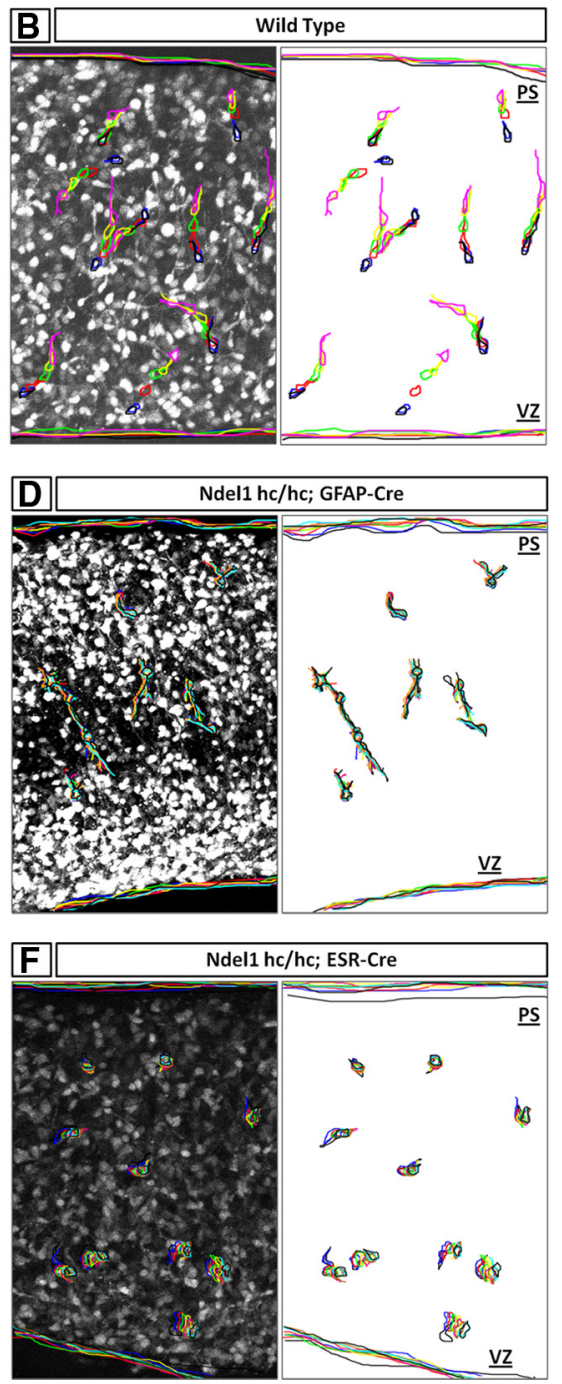

Figure 4. Impairment of migration in hGFAPCre- and CreER-induced knock-out of Lis1 and Ndel1. Merged images of cell migration (each color indicates $90 \mathrm{~min})(\boldsymbol{A})$ and merged images of those panels for migration of wild-type cells $(\boldsymbol{B})$ are shown. Neuronal migration in GFAP-Cre; Lis $7^{\text {hc/hc }}(\boldsymbol{C})$ and GFAP-Cre;Ndel $7^{\text {h//hc }}$ cortical slices (D) is shown. Migration was completely

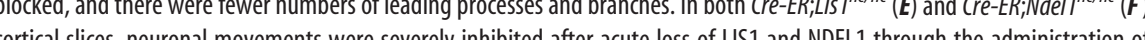
tamoxifen by intraperitoneal injection of pregnant dams. The last images (green) were not different in position compared to the first boundary images (black) in cells from Cre-ER; $L i s 7^{\text {hc/hc }}$ and Cre-ER;Ndel $7^{\text {hc/hc }}$ cortical slices.

in tangential and VZ directions, respectively. In contrast, in Lis $1^{+/ k o}$ and Lis ${ }^{h c / k o}$ slices, tangential migration velocities were 54. $96 \pm 6.72$ and $12.79 \pm 8.41 \mu \mathrm{m} / \mathrm{h}$, respectively, while in VZ-directed migration, velocities were $38.04 \pm 2.45$ and $20.81 \pm$ $0.36 \mu \mathrm{m} / \mathrm{h}$, respectively. Velocities of migrating neurons from $\mathrm{Ndel} \mathrm{h}^{\text {hc/ko }}$ cortical slices averaged $40.9 \pm 20.35 \mu \mathrm{m} / \mathrm{h}$ during tangential migration and $36.56 \pm 17.87 \mu \mathrm{m} / \mathrm{h}$ during VZ-directed migration (Fig. $5 B, C$ ).

These velocities were calculated only for moving neurons. The severe effects of reduction of doses of Lis1 and Ndel1 on migration were also evident when examining the proportion of moving cells (Fig. $5 D$ ). In wild-type cortical slices, $\sim 60 \%$ of labeled cells in the IZ were moving, and the ratio of radial:tangential:VZ directed cells was $\sim 3: 2: 1$. In contrast, only $20 \%$ and $9 \%$ of cells were moving in $L i s 1^{+/ k o}$ and $L i s 1^{h / k o}$ slices, and all directions of movement were affected. In Ndel1 ${ }^{\text {hc/ko }}$ slices, the number of moving cells was reduced to $50 \%$, and interestingly, this reduction was mostly due to a decrease in tangentially migrating cells (Fig. 


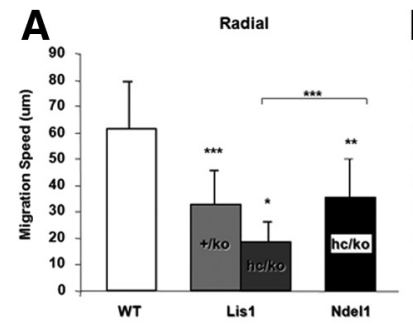

Dercentage of Moving Cells
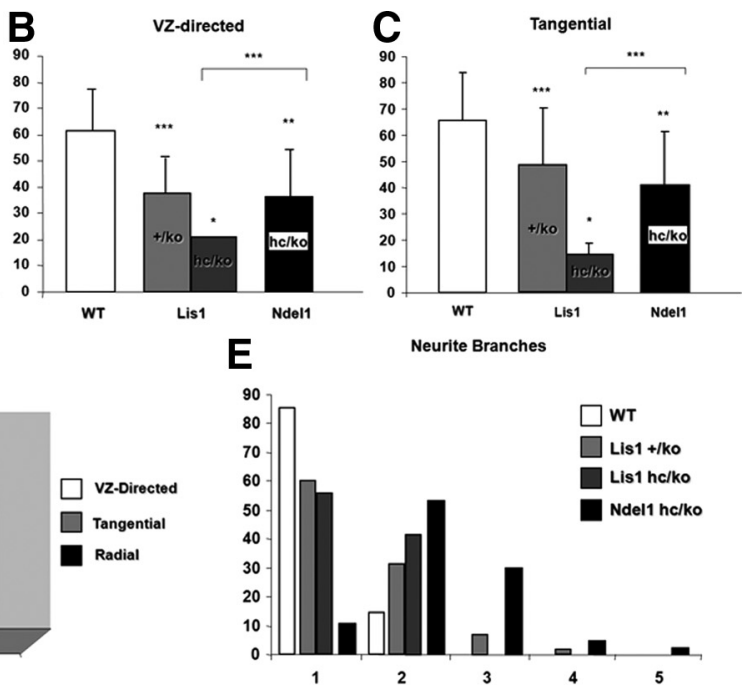

Neurite Branches

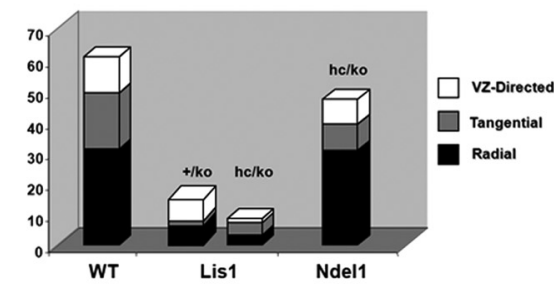

F

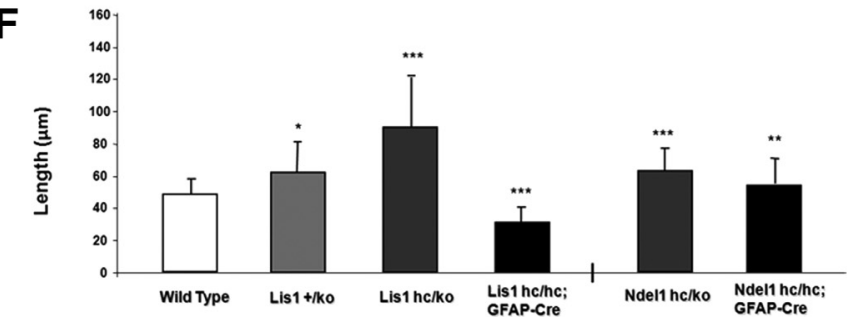

Figure 5. Quantitation of movement, branching and neurite length of neural precursor cells undergoing neuronal migration. Average migration speed and SD of cells from wild-type, Lis1 (+/ko with 50\% and hc/ko with 35\% of wild-type LIS1 levels) and Ndel1 (hc/ko with 35\% of wild-type NDEL1 levels) mutants undergoing radial (A), VZ-directed (B), and tangential (C) migration. $\boldsymbol{D}$, The total number of moving cells and the proportion of moving cells in each genotype that were moving in radial, VZ-directed or tangential directions is shown. $\boldsymbol{E}$, The percentage of migrating neural precursor cells with secondary branches in each genotype is shown. Note that in $\mathrm{Ndel}^{\mathrm{hc} / \mathrm{ko}}$ cells, $90 \%$ of cells had more than one secondary branch and often had multiple branches, while in Lis ${ }^{h c / k o}$ cells, less than half had more than one branch and very few had more than two branches. $\boldsymbol{F}$, Left of the hash mark: the length of the major leading process was extended in neural precursor cells from Lis ${ }^{+/ k o}$ (light gray bar) and Lis $7^{\text {hc/ko }}$ (dark gray

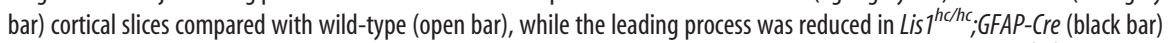
cells. Right of the hash mark: the length of major leading process was extended in neural precursor cells from Ndel $7^{\text {hc/ko }}$ (dark gray bar) and in Ndel1 ${ }^{h c / h c}$;GFAP-Cre (black bar) cortical slices compared to wild type. ${ }^{*} p<0.05$; ${ }^{* *} p<0.005,{ }^{* * *} p<0.0005$ (Student's $t$ test).

5D). As noted above, in complete loss-of-function mutants, there was a complete absence of movement (Fig. 4). Partial reduction of Lis1, and Ndel1 in particular, resulted in an increase in neuronal precursors with bi- or multipolar morphologies due to secondary branching from a primary neuronal process. In wild-type cortical slices, $\sim 15 \%$ or cells displayed a bipolar morphology. In contrast, $80 \%$ of migrating neuronal precursors from $N d e l 1^{h c / k o}$ slices displayed bi- or multipolar shapes, while in $L i s 1^{+/ k o}$ and Lis $1^{h c / k o}$ slices, only $35 \%$ and $45 \%$ of migrating neuronal precursors displayed bi- or multipolar morphologies, respectively (Fig. 5E). The majority of cells in either of the Lis1 mutants displayed at most two neurite secondary branches, but a similar number of Ndel1 mutant cells had either two more than two secondary branches (Fig. $5 E$ ). Thus, reduction of Lis 1 or Ndel1 resulted in a decreased velocity of neuronal migration, a reduction in the proportion of migrating neurons, and an increase in neuronal precursors with secondary bi- or multipolar morphologies, particularly in Ndell mutants. The multidirectional and longer extension of the leading process in migrating neuronal precursors in $\mathrm{Ndel}^{\mathrm{hc} / \mathrm{ko}}$ slices likely contributes to the retardation of cell body moving from the branch point into new leading direction.

\section{Abnormal lengths of leading processes in cortical slices from Lis1 and Ndel1 mutants}

In addition to a reduction in migration speed and numbers of migrating cells, the reduction of dosage of Lis1 or Ndell resulted in abnormalities in the lengths of leading processes. These lengths were $47.04 \pm 12.68 \mu \mathrm{m}$ for wild-type cells, $61.92 \pm 22.86 \mu \mathrm{m}$ for Lis $^{+/ k o}$ cells $(p<$ $0.05), 90.64 \pm 29.73 \mu \mathrm{m}$ for $L i s 1^{\text {hc/ko }}$ cells $(p<0.0005)$, and $29.21 \pm 7.7 \mu \mathrm{m}(p<$ $0.0005)$ for Lis1-null cells (Fig. 5F). Similar Lis1-dose-dependent increases in lengths of the leading processes were found if the cells were separated into those that migrated in radial, tangential or VZdirected patterns (data not shown). These results demonstrated that Lis 1 reduction resulted in dose-dependent elongation of leading processes, unless there was complete absence of Lis1, which resulted in slightly shorter leading processes.

The lengths of leading processes of wild-type, Ndel1 ${ }^{h c / k o}$ and Ndel1-null cells were $47.16 \pm 17.03 \mu \mathrm{m}, 60.18 \pm 25.63$ $\mu \mathrm{m}(p<0.0005)$ and $53.82 \pm 15.85 \mu \mathrm{m}$ $(p<0.005)$, respectively (Fig. $5 F)$, demonstrating that reduction of Ndel1 also resulted in significantly increased lengths of leading processes of migrating neurons, similar to Lis1 mutants.

\section{Migration defects of neuronal precursors from neurospheres in tamoxifen-Cre induced Lis1 and Ndel1 knock-out mice}

To more closely examine migration behavior in isolated precursor cells, we measured the outgrowth of precursor cells migrating outward from attached neurospheres. Neuronal precursor cells from control Lis ${ }^{h c / h c}$ embryonic cortex, treated with tamoxifen, actively migrated in a radial pattern from the neurospheres with a broad range of outgrowth (Fig. 6A). In contrast, neuronal migration was inhibited in neuronal precursor cells isolated from Lis ${ }^{h c / h c}$;Cre-ER treated at the time of attachment with low (10 pM) and high dose (100 nM) of 4-hydroxy tamoxifen (Fig. 6B). The distance of the leading edge of migrating cells was measured from the center of the neurosphere (see lines in Fig. $6 A, B$, top panels). Neuronal precursor cells from control Lis $1^{h c / h c}$ embryonic cortex treated with $10 \mathrm{pM}$ 4-hydroxy tamoxifen migrated an average of $878.64 \pm 90.32 \mu \mathrm{m}$ in $24 \mathrm{~h}$, while similar treatment of cells from Lis $1^{\text {hc/hc }}$;Cre-ER cortices resulted in migration of only $319.19 \pm 166.2(p<0.01)$. Treatment with 100 nm 4-hydroxy tamoxifen resulted in suppression of migration of both genotypes, but again migration of the mutant cells $(571.43 \pm 66.63 \mu \mathrm{m})$ was inhibited to a much greater extent than controls $(181.6 \pm 48.43 \mu \mathrm{m}, p<0.01)$ (Fig. $6 E)$. The marginal areas of outgrowth displayed many differentiated cell types in $L i s 1^{h c / h c}$;Cre-ER, and these cells were stationary, blocking the further migration of precursor cells. For example, GFAP-positive fibers from control $L i s 1^{\text {hc/hc }}$ cells were mainly oriented in the direction of movement (Fig. 6F). In con- 

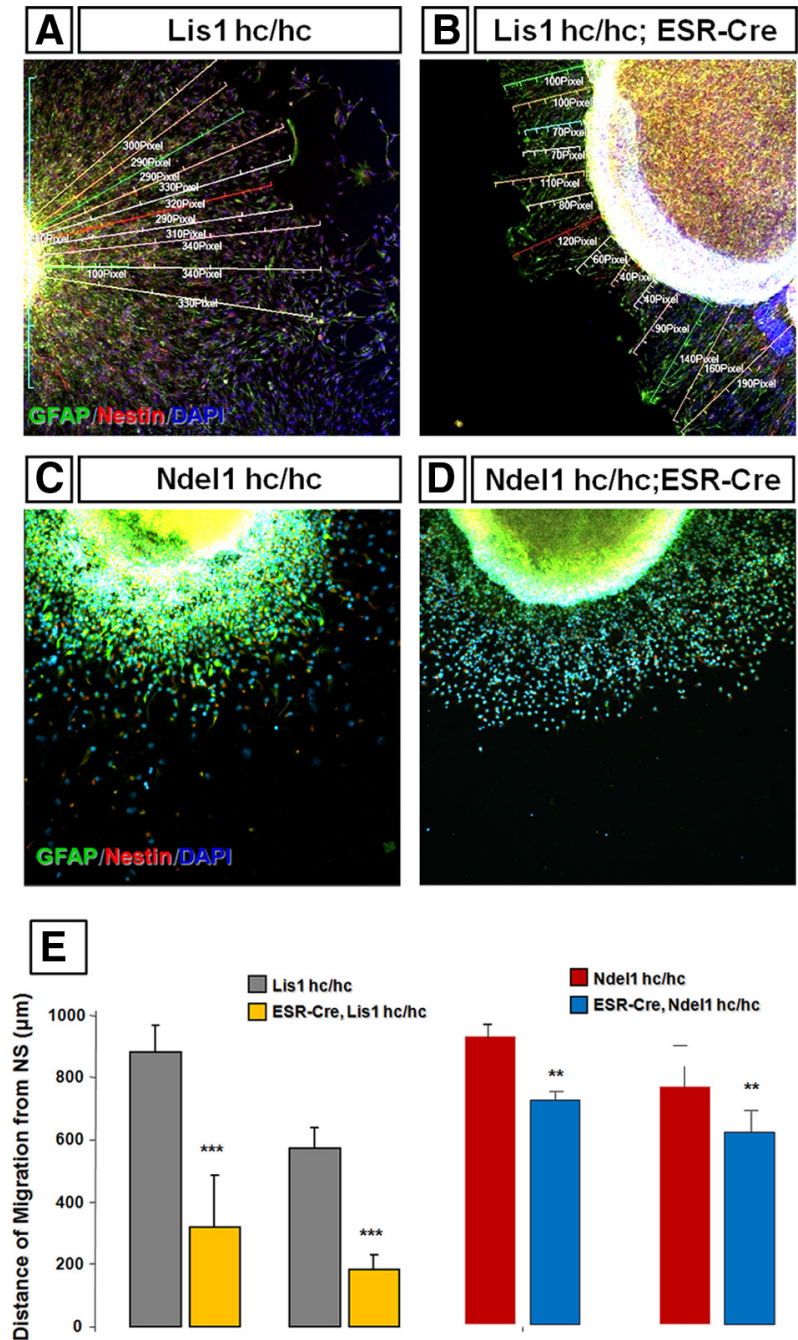

$10 \mathrm{pM}$

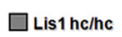

$\square$ ESR-Cre, Lis1 hc/hc

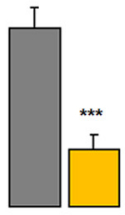

$100 \mathrm{nM}$

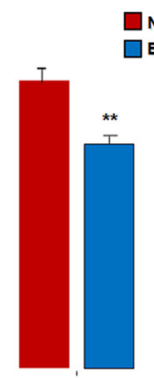

$10 \mathrm{pM}$
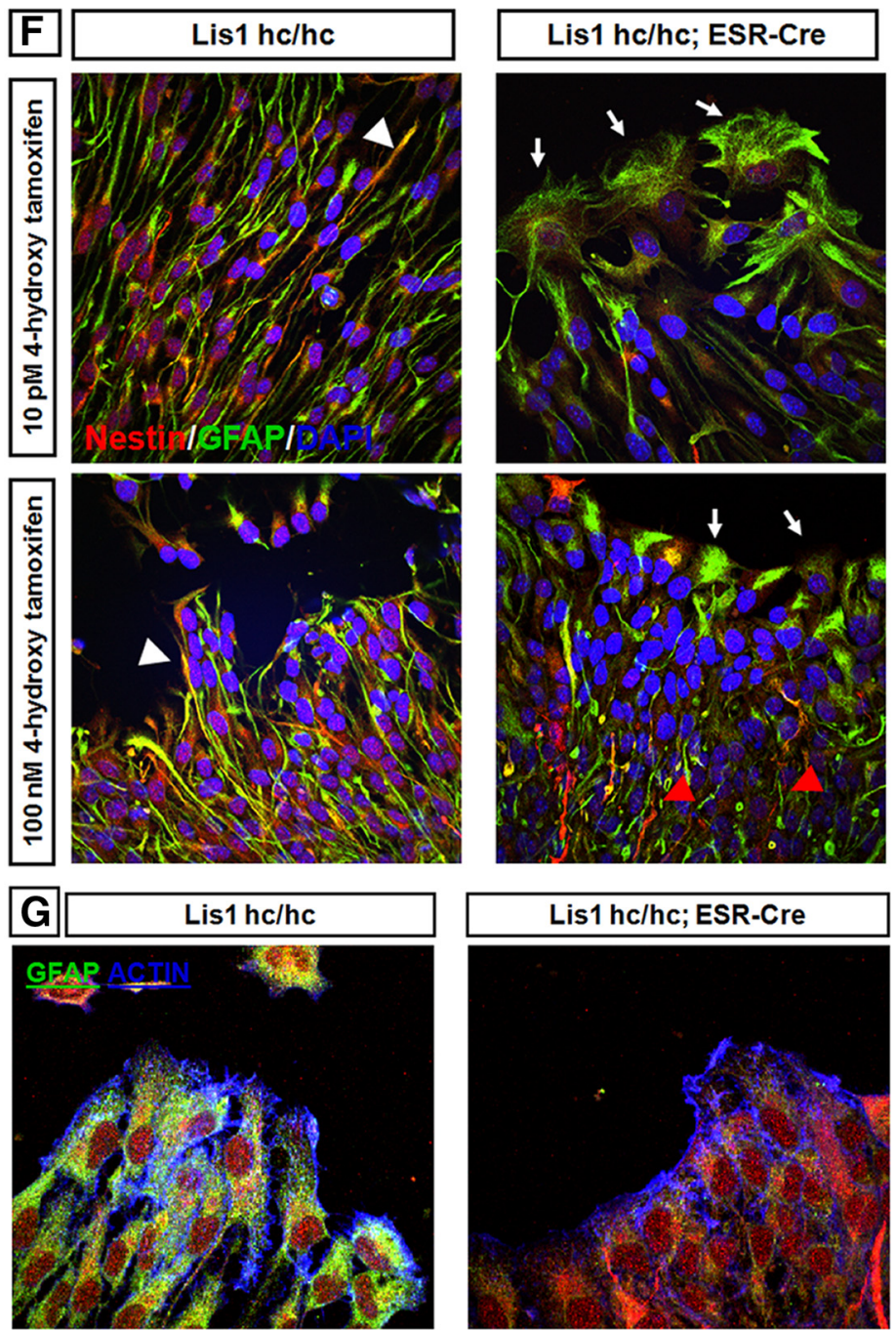

Figure 6. Migration defects of neurospheres of neuronal progenitors attached to the substratum from conditional knock-out mice for $L i$ is 1 or $N d e l 1$ with or without $C r e-E R$ after tamoxifen-induced

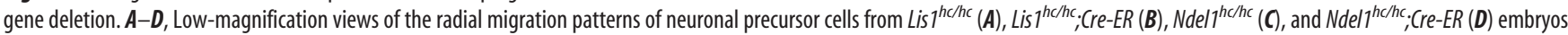
treated with low (10 pm) doses of 4-hydroxy tamoxifen. The distance of radial movement of individual cells is indicated by individual white lines. Immunocytochemical staining is with GFAP ( $g r e e n$ ),

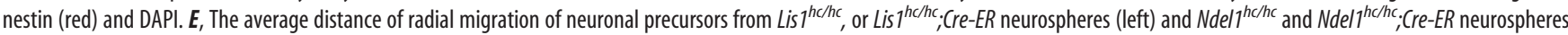
(right) treated with low (10 pm) and high doses (100 nm) of 4-hydroxy tamoxifen, as indicated at the bottom of the panel. $\boldsymbol{F}$, Early appearance of differentiated cells in Lis ${ }^{\text {hc/hc }}$; $($ re-ER neurosphere outgrowths. In cells from Lis $7^{\text {hc/hc }}$ embryos after 4-hydroxy tamoxifen treatment, nestin- (red) and GFAP- (green) positive cells were oriented radially, and the nuclei were elongated in the same direction. In contrast, in cells from Lis ${ }^{\text {hc/hc }}$; Cre-ER embryos treated with 4-hydroxy tamoxifen, there were strong GFAP-positive cells localized in marginal area of outgrowth, with fewer nestinpositive cells that were disconnected and short glial fibers, and nuclei were more rounded in appearance. G, Actin protrusion was obvious in migrating cells from $L$ is $7^{\text {hc/hc }}$ embryos, but blunt ended actin bundles were observed in cells from Lis $^{\text {h/hc }}$; Cre-ER embryos.

trast, most GFAP fibers in Lis ${ }^{h c / h c}$; Cre-ER cells were blunt, thicker, and multidirectional (Fig. $6 F$ ). Actin-rich protrusions at the leading edge of $L i s 1^{h c / h c}$; Cre-ER cells were also blunt and cells appeared to tightly adhere to each other, inhibiting forward migration (Fig. 6G).

Complete loss of Ndel1 also significantly inhibited the migration of neuronal precursor cells from neurospheres (Fig. 6C,D). Neuronal precursor cells from control $N d e l 1^{h c / h c}$ embryonic cortex treated with $10 \mathrm{pm}$ and $100 \mathrm{~nm} 4$-hydroxy tamoxifen migrated an average of $893.99 \pm 46.34 \mu \mathrm{m}$ and $739.61 \pm 74.96 \mu \mathrm{m}$ in $24 \mathrm{~h}$, while similar treatment of cells from Ndel1 ${ }^{\text {hc/hc }}$;Cre-ER cortices resulted in migration distances of only $696.77 \pm 36.39 \mu \mathrm{m}(p<$ $0.01)$ and $597.62 \pm 50.23 \mu \mathrm{m}(p<0.01)$ (Fig. $6 E)$. These results demonstrate that complete loss of either Lis1 or Ndel1 resulted in a severe retardation of migration in vitro from neural precursor cells in culture, but the migration of neuronal precursors in
Ndell $1^{h c / h c}$;Cre-ER treated with both low and high doses of tamoxifen was not as severely affected as $L i s 1^{h c / h c}$;Cre-ER tamoxifentreated cells.

\section{Abnormal polarization of MTOC and increased nuclear-centrosomal (N-C) distance cells in \\ Lis 1 and Ndel1 mutant cells}

In migrating cells, the polarization of the MTOC has an important role in determining the direction and pattern of cell movements (Etienne-Manneville and Hall, 2001). We measured the percentage of cells that displayed polarity of MTOC outward and away from the neurospheres in the marginal area of the outgrowths. The percentage of polarized MTOCs in the control Lis $1^{h c / h c}$ and $N d e l 1^{h c / h c}$ neuronal precursors was $>80 \%$. However, the percentage of polarized MTOCs was significantly reduced to $<50 \%$ both in Lis1 ${ }^{h c / h c}$;Cre-ER and Ndell ${ }^{h c / h c}$;Cre-ER neuro- 

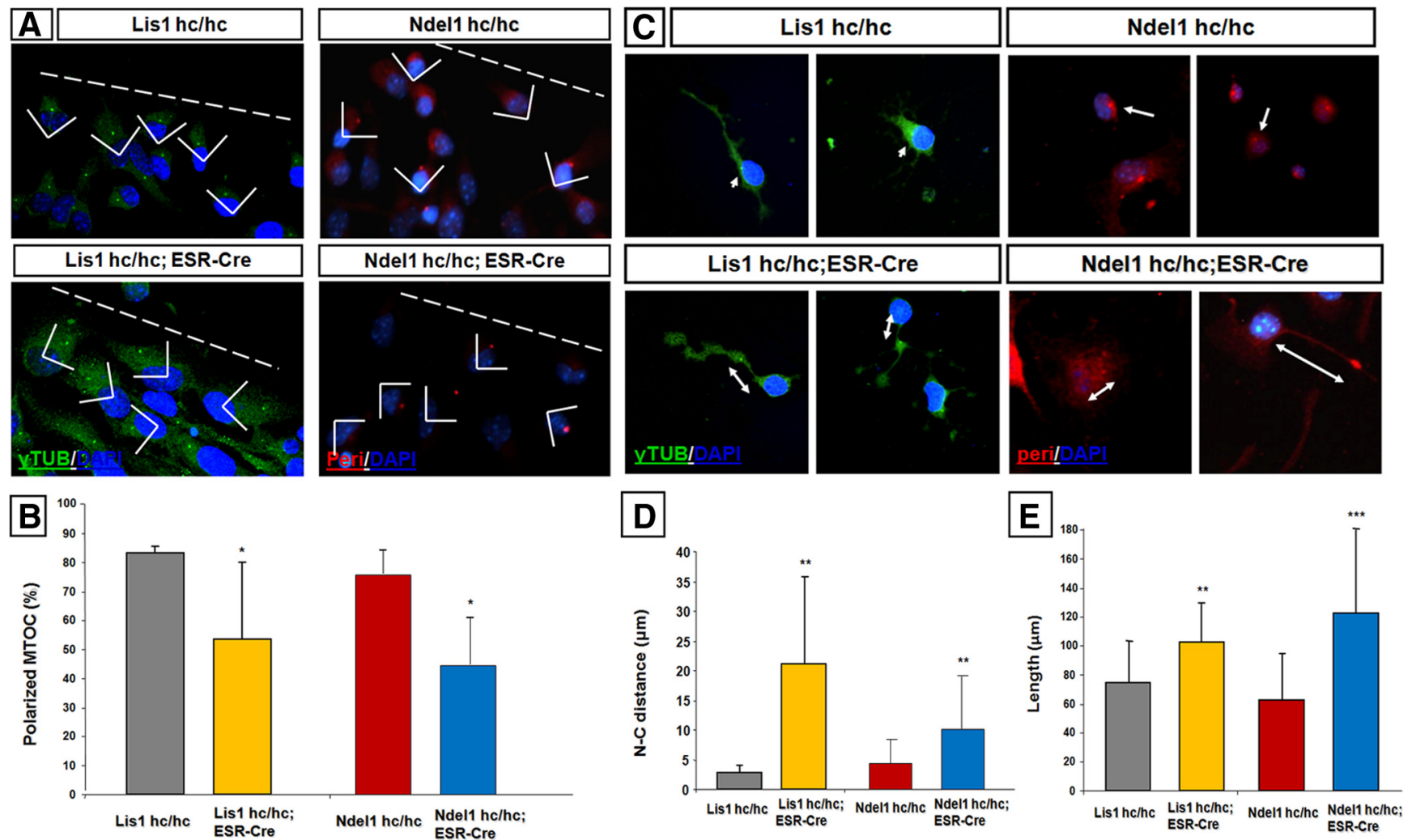

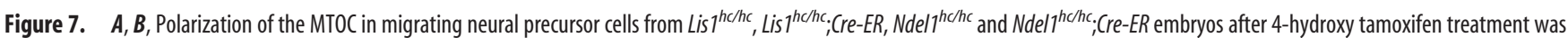
measured. The orientation of the centrosome preceding the nucleus was measured based upon the frontier line of the outgrowth area, rather than the line of the wound in wound-healing studies of fibroblasts in culture as described previously (Etienne-Manneville and Hall, 2001) In controls, the MTOC was well polarized in $>80 \%$ of cells. However, the polarization was significantly disrupted $(<50 \%)$ both in neuronal progenitor cells from Lis $7^{h / / h c} ; C r e-E R$ and $N d e / 1^{h c / h c} ; C r e-E R$ embryos. $C, D$, Distance between the nucleus and centrosome (N-C distance) of neural stem cells. The N-C

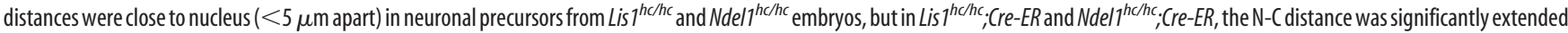

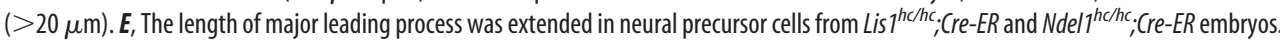

sphere outgrowths treated with $10 \mathrm{pm}$ tamoxifen (Fig. $7 A, B$ ), demonstrating the lack of uniform polarization of these migrating cells at the leading edge of the neurosphere outgrowths. The distance between the nucleus and the centrosome ( $\mathrm{N}-\mathrm{C}$ distance) is an index for the function of MTOC in moving cells, and it is extended in Lis1 and Ndel1 mutants, as previously shown (Shu et al., 2004; Tanaka et al., 2004; Sasaki et al., 2005). Consistent with these findings, the $\mathrm{N}-\mathrm{C}$ distance was significantly extended in neurons from $L i s 1^{h / h c}$; Cre-ER or Ndel1 ${ }^{\text {hc } / h c} ; C r e-E R$ neurospheres treated with low and high dosage of tamoxifen (Fig. 7C). The N-C distances in control Lis ${ }^{h c / h c}$ or Ndel1 ${ }^{\text {hch } h c}$ cells were always $<5$ $\mu \mathrm{m}$ from the nucleus. However, in $L i s 1^{h c / h c}$; Cre-ER cells, the N-C distance was greatly extended to $>20 \mu \mathrm{m}$, while in Ndel1 ${ }^{\text {hc/hc }}$; $C r e-E R$ cells, the N-C distance was also extended to $>10 \mu \mathrm{m}$, less than that of Lis $1^{h c / h c}$; Cre-ER cells (Fig. 7C,D). The length of leading processes for control cells from Lis $1^{\text {hc/hc }}$ and Ndell $1^{\text {hc/hc }}$ were $76.43 \pm 28.99 \mu \mathrm{m}$ and $59.72 \pm 32.71 \mu \mathrm{m}$, respectively, while cells from Lis ${ }^{\text {hc/hc }} ; \mathrm{Cre}-E R$ and $\mathrm{Ndel1}{ }^{\text {hc/hc }} ; \mathrm{Cre}-E R$ the lengths were $98.32 \pm 33.42 \mu \mathrm{m}$ and $114.39 \pm 54.26 \mu \mathrm{m}$, respectively (Fig. $7 E$ ). These results confirm those from live imaging and demonstrated that Lisl and Ndell reduction resulted in longer leading processes in vitro.

\section{Discussion}

The major cause of the human cortical malformation lissencephaly, or "smooth brain" is a migration defect of postmitotic neurons (Wynshaw-Boris, 2007). Studies in a variety of model systems have helped to define an important role for LIS1 as part of an evolutionarily conserved protein complex that regulates dynein motor function (Gupta et al., 2002; Vallee and Tsai, 2006). In addition to LIS1 and dynein subunits, this complex also contains NDEL1 and NDE1, the two mammalian homologues of the nuclear distribution gene E, nudE, discovered first in Aspergillus nidulans. Genetic mutants of Lis1 and Ndel1 in the mouse have provided important insights into the role of LIS1 and its complex in brain development. For example, we have previously produced null and hypomorphic conditional genetic mutants of Lis 1 (Hirotsune et al., 1998) which have allowed us to make mice with graded reduction and complete loss of Lis1 in vivo. Mice with decreased levels of Lis1 exhibited dose-dependent disorganized cortical layers, hippocampus, cerebellum, and olfactory bulb due to cell-autonomous neuronal migration defects (Hirotsune et al., 1998, Gambello et al., 2003), and are a good model for the human disorder. Complete loss of LIS1 results in peri-implantation lethality, a result confirmed in another Lis 1 knock-out (Cahana et al., 2001), demonstrating that Lis1 is an essential gene. Similar studies were performed with an allelic series of Ndel1 (Sasaki et al., 2005), demonstrating that Ndell is also important for neuronal development and is an essential gene. These and other studies support the conclusion that there are in vivo migrational defects in mice with reduction of Lis1 or Ndel1 dosage (Hirotsune et al., 1998, Gambello et al., 2003; Tanaka et al., 2004).

More direct evidence for a role for Lisl and Ndell in neuronal migration was provided using time lapse imaging of migrating neurons in vitro in cerebellar granule cells isolated from Lis $1 \mathrm{mu}-$ 
tant mice (Sasaki et al., 2005) or in embryonic cortical slices after RNAi-mediated knock-down of Lis1 and Ndel1 (Shu et al., 2004; Tsai et al., 2005, 2007). Cerebellar granule cells from $L i s 1^{+/-}$mice displayed slowed migration, and a lengthening of the N-C distance (Tanaka et al., 2004), and consistent with an important role in dynein function, inhibition of dynein by overexpression of dynamitin resulted in a similar phenotype. RNAi knockdown studies of Ndel1, Lis1 or dynein impaired neuronal positioning and caused the uncoupling of the centrosome and nucleus (Shu et al., 2004, Tsai et al., 2005, Tsai et al., 2007), similar to our studies with Lis1 mutants. However, the disruption of cortical neuronal migration has not been studied in Lis1 and Ndell genetic mutant mice. There are several important advantages to the use of genetic mutants to study neuronal migration mutants. First, genetic mutants allow for the precise control of levels of gene products, using null, hypomorphic and conditional alleles, as we have shown for Lis 1 (Hirotsune et al., 1998; Gambello et al., 2003; Yingling et al., 2008), while siRNA knock-down results in variable levels of activity. Second, all cells have the same level of gene product, while most siRNA protocols result in variable levels of knock-down in a variable proportion of cells in a tissue. Finally, any time of development can be studied, while most siRNA protocols target radial glial stages of neurogenesis, and would not allow for the study of gene disruption in earlier time points such as neuroepithelial stem cells (Yingling et al., 2008).

Here, we investigated the cortical migration phenotypes of mice with partial or complete loss of Lis1 or Ndel1, using genetic mutants rather than siRNA-mediated knockdown. This allowed us to examine the effect of precise, reproducible levels of LIS1 and NDEL1 in all cells in the developing brain, using histological analysis, cortical slice cultures and neurosphere assays. Our results confirm and extend previous findings, while they also provide novel insights into the roles of LIS1 and NDEL1 in brain development and neuronal migration.

One of our unique findings is that mutants with complete loss of Lis 1 and Ndel1 display similar brain defects histologically (Fig. 1). There are more severe hippocampal defects in Lis1 mutants than Ndel1 mutants. The severe hippocampal defects found in mutants with complete loss of Lis 1 is the result of extreme sensitivity of neuroepithelial stem cell neurogenesis to the loss of Lis1 (Yingling et al., 2008). The less severe hippocampal phenotype displayed by Ndel1 mutants is likely due to redundancy of Nde1 with Ndel1. Nde1 is an ortholog of Ndel1 that also acts as a binding partner in LIS1/dynein complex. Mice with complete disruption of Nde1 are viable and display microcephaly with small superficial cortical layers II-IV, and a modest defect of neuronal migration (Feng and Walsh, 2004). Although we believe that redundancy between Ndell and Nde1 is the most likely explanation for the milder phenotype of Ndel1 mutants compared to Lis1 mutants, it is also possible that these differences in phenotypes result from some differences in the functions of Lis1 and Ndel1 (see below).

Importantly, we found dose-dependent migration defects in both Lis1 (Figs. 2, 4) and Ndel1 (Figs. 3, 4) mutants in vivo in cortical slices as well as in vitro in neurosphere assays, and there were unique patterns of migration defects seen in the two mutants. We analyzed migration patterns using in vivo time lapse imaging of migrating neurons in cortical slices of three types of directional migration: radial, tangential and VZ-directed migration during mid-embryonic stage (E14.5). Neurons in Lis $1^{\text {ko/+ }}$ cortical slices, with $50 \%$ of wild-type LIS1 protein levels, displayed an abnormal pattern of migration with long and curved leading processes to probe the areas in front of migration. These findings are

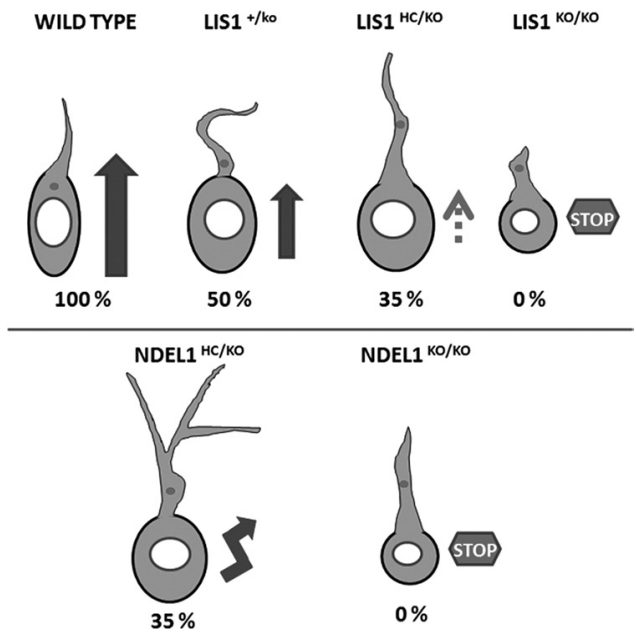

Figure 8. Distinct migration models of neurons in Lis1 and Ndel1 knock-out mice. Genotypes are above the cells, speeds of migration relative to wild-type are at the bottom of the cells, and the speed and direction of movement is indicated by the size and thickness of the arrow. "STOP" means that the cells did not move. Note the lengthened and curled processes of the Lis1 mutants, while the Ndel1 mutants displayed branching. Wild-type cells have an actively migrating elongated shape of the cell body, which is short, thin and moves straightforward into the leading process while maintaining a short $\mathrm{N}-\mathrm{C}$ distance (centrosome; small dot and nucleus; circle). Lis $1+/$ ko cells, which express $50 \%$ of wild-type LIS1 protein levels display a curved and thicker leading process with longer $\mathrm{N}-\mathrm{C}$ distance, and Lis $1 \mathrm{hc} / \mathrm{k0}$ (35\% of Lis 1 protein) cells are mostly inactive with a thick leading process and a longer $\mathrm{N}-\mathrm{C}$ distance. Ndel $\mathrm{hc} / \mathrm{ko}$ cells display a multibranched leading process, a zig-zag moving pattern and longer $\mathrm{N}-\mathrm{C}$ distance. In the absence of either Lis1 or Ndel1, the neuronal precursor cells did not substantially move. Thickness of the arrows indicates velocity of individual cells.

similar to those found in cerebellar granule cells from $L i s 1^{k o /+}$ mice, which displayed a slowed migration and extended distance between the centrosome and the nucleus (Hirotsune et al., 1998; Gambello et al., 2003; Tanaka et al., 2004). These findings were also similar to the migration defects of neuronal precursor cells from siRNA-mediated Lis1 knock down (Tsai et al., 2005). In cortical slices from Lis $1^{h c / k o}$ mice, with $35 \%$ of wild-type LIS1 protein, most neuronal progenitor cells in IZ did not move, and also display an even longer leading process. In fact, the percentage of cells moving in the IZ is almost zero in $L i s 1^{\text {hc/ko }}$ cortical slices. Neurons from cortical slides of Lis ${ }^{h c / h c} ; h G F A P-C r e$ and Cre-ER embryos displayed an even more severe complete lack of migration.

Consistent with previous findings in Lis 1 mutant granule cells (Tanaka et al., 2004), Ndell mutant cells (Sasaki et al., 2005) or siRNA inhibition of Lis1 and Ndel1 (Shu et al., 2004; Tsai et al., 2007), loss of either Lis1 or Ndell resulted in defects in MTOC positioning and $\mathrm{N}-\mathrm{C}$ distance defects using an in vitro neural sphere assay. These defects were more severe in Lis1 than Ndell mutants, which again is likely to be the result of functional redundancy of Nde1 with Ndell. Most of the cells in the marginal outgrowth area of migrating neural precursor cells from Lis $1^{\text {hc/hc }}$;Cre-ER neural spheres after 4-hydroxy tamoxifen treatment are morphologically differentiated with large cell bodies with round nuclear shapes. These findings confirm the lack of migration of neurons completely missing Lis1, since rounded nuclear morphology is characteristic of cells that are not actively moving, in contrast to the elongated shape of nuclei in actively migrating cells. Similar results were found after complete loss of Ndel1, which also resulted in the significant inhibition of the migration of neuronal progenitor cells from neurospheres. Additionally, the $\mathrm{N}-\mathrm{C}$ distance was extended and the polarity of 
MTOC in marginal outgrowth areas of attached neural spheres was defective in both $L i s 1^{h c / h c} ; \mathrm{Cre}-E R$ and $\mathrm{Ndel}^{h c / h c} \mathrm{Cre}$-ER cells after 4-hydroxy tamoxifen treatment. In addition to these already described findings, the neural sphere migration assays also uncovered loss of polarization of the MTOC in the migrating cells from both Lis1 and Ndel1 mutants. This abnormal polarization of the MTOC is likely an important factor in the impairment of the migration behavior of moving cells, since it is known that MTOC polarization is important for the directional movement of diverse cell types (Etienne-Manneville and Hall, 2001; Gomes et al., 2005).

Previous studies with siRNA-mediated knock-down found similar migration defects after reduction of either Lis1 or Ndel1, with both mutants displaying severe reduction of motility. In our study, genetic reduction of Ndell dosage resulted in unique multipolar and secondary branching defects not seen previously with siRNA knockdown. Neurons from Ndell ${ }^{h c / k o}$ corical slices displayed a distinct zig-zag pattern migration and displayed branched migration. The majority of cells from Ndel1 ${ }^{h c / k o}$ cortical slices displayed multiple directional changes and had several leading processes with splitting of the distal ends of those processes. This results in cells that change moving directions frequently, and reduces their speed of movement. Normally, migrating cells move in one direction toward a single leading process, but migrating cells from $N d e l 1^{h c / k o}$ slices exhibited several branches. The formation of multiple branches likely contributed to the inhibition of migration of neurons from Ndel1 mutants, and the inability to form a single main leading process probably results from an abnormality of MTOC to properly polarize the neuron and mobilize the forces needed for a unified directional movement. Although Lis $^{+/ k o}$ mutants displayed some curling of leading processes (Fig. 2), the branched migration pattern and multipolar morphology seen in cells from Ndel1 mutants was a distinct phenotype, and may reflect some differences in the functions of Lis1 and Ndel1 in migration. These branched migration movements of neurons from Ndell $1^{h c / k o}$ mice were similar to the behavior of neurons from p35 (an activator of cyclin-dependent kinase 5 , Cdk5)-deficient mice, where $\sim 90 \%$ of p35 deficient neurons displayed branched migration (Gupta et al., 2003). Among moving Ndel1 ${ }^{\text {hc/ko }}$ cells in IZ, $80 \%$ of cells had bi- or multipolar processes, consistent with the multipolar migration of neurons from $p 35^{-1-}$ mice (Gupta et al., 2003). The similarity in phenotype is likely due to the phosphorylation of NDEL1 as a substrate of Cdk5/p35 (Niethammer et al., 2000; Sasaki et al., 2000). These results are consistent with a recent report showing that NDEL1 was required for neuronal migration as a target molecule of Cdk5/p35 phosphorylation (Sasaki et al., 2000; Niethammer et al., 2000; Toyo-oka et al., 2003; Toyo-Oka et al., 2005).

In addition to neuronal migration, LIS1 and NDEL1 are important for neurite extension (Gupta et al., 2002; Ayala et al., 2007). Our results extend these observations and demonstrate a dose-dependent role for LIS1 and NDEL1 in regulating and constraining neurite outgrowth. NDEL1 is a key protein in the vimentin/dynein complex formed during neurite extension by interacting with LIS1 and the vesicular protein $\alpha \mathrm{COP}$ (Shim et al., 2008), suggesting that NDEL1 has an important role for forming a leading process through vimentin transport during cell migration. Recently, we reported that NDEL1 phosphorylation by the mitotic kinase Aurora A plays an essential role during neurite extension (Mori et al., 2009). Aurora A is activated and phosphorylates NDEL1 which then stimulates microtubule extension for neurite formations. Phosphorylation of Aurora A by atypical protein kinase $\mathrm{C}(\mathrm{aPKC})$ is necessary to activate Aurora A, sug- gesting that an aPKC-Aurora A-NDEL1 pathway is important for the control of microtubule organization during neurite extension. In addition, LIS1 and dynein play a key role in microtubule advance during growth cone remodeling in axonogenesis (Grabham et al., 2007). The precise molecular mechanisms responsible for these effects on neurite elongation are not known at present, but our demonstration of the involvement of LIS1 and NDEL1 in this process provides an important entry point to examine these mechanisms.

Our findings add to the wealth of data supporting the conclusion that neuronal migration is mediated by a LIS1-NDEL1 complex regulating cytoplasmic dynein function, a function that is conserved through evolution from Aspergillus to mammals (for review, see Gupta et al., 2002; Vallee and Tsai, 2006; WynshawBoris, 2007). We can summarize the defects we found during neuronal migration in cortical slices from Lis1 and Ndel1 mutant embryos in this study (Fig. 8). Compared to wild-type mice, there is a dose-dependent reduction in speed of neuronal migration in both Lis1 and Ndel1 mutant cortices associated with lengthening of the $\mathrm{N}-\mathrm{C}$ distance and bulging near the soma. Neuronal progenitors with $50 \%$ of LIS1 protein display a curved leading process, while further reduction to $35 \%$ results in mild branching of the leading process, although the neurons migrate mostly in a straight pattern. Reduction of LIS1 protein from 50 to $35 \%$ results in progressive elongation of the leading process. In contrast, reduction of NDEL1 to $35 \%$ results in multiple forks in the leading process and an unfocused, branched pattern of migration with frequent direction changes. Complete loss of either LIS1 or NDLE1 results in no detectable neuronal movement and short leading processes.

\section{References}

Ayala R, Shu T, Tsai LH (2007) Trekking across the brain: the journey of neuronal migration. Cell 128:29-43.

Cahana A, Escamez T, Nowakowski RS, Hayes NL, Giacobini M, von Holst A, Shmueli O, Sapir T, McConnell SK, Wurst W, Martinez S, Reiner O (2001) Targeted mutagenesis of Lis1 disrupts cortical development and LIS1 homodimerization. Proc Natl Acad Sci U S A 98:6429-6434.

Calaora V, Rogister B, Bismuth K, Murray K, Brandt H, Leprince P, Marchionni M, Dubois-Dalcq M (2001) Neuregulin signaling regulates neural precursor growth and the generation of oligodendrocytes in vitro. J Neurosci 21:4740-4751.

Engele J, Bohn MC (1992) Effects of acidic and basic fibroblast growth factors (aFGF, bFGF) on glial precursor proliferation: age dependency and brain region specificity. Dev Biol 152:363-372.

Etienne-Manneville S, Hall A (2001) Integrin-mediated activation of Cdc42 controls cell polarity in migrating astrocytes through PKCzeta. Cell 106:489-498.

Feng Y, Walsh CA (2004) Mitotic spindle regulation by Nde1 controls cerebral cortical size. Neuron 44:279-293.

Gambello MJ, Darling DL, Yingling J, Tanaka T, Gleeson JG, Wynshaw-Boris A (2003) Multiple dose-dependent effects of Lis1 on cerebral cortical development. J Neurosci 23:1719-1729.

Gomes ER, Jani S, Gundersen GG (2005) Nuclear movement regulated by Cdc42, MRCK, myosin, and actin flow establishes MTOC polarization in migrating cells. Cell 121:451-463.

Grabham PW, Seale GE, Bennecib M, Goldberg DJ, Vallee RB (2007) Cytoplasmic dynein and LIS1 are required for microtubule advance during growth cone remodeling and fast axonal outgrowth. J Neurosci 27:5823-5834.

Gupta A, Tsai LH, Wynshaw-Boris A (2002) Life is a journey: a genetic look at neocortical development. Nat Rev Genet 3:342-355.

Gupta A, Sanada K, Miyamoto DT, Rovelstad S, Nadarajah B, Pearlman AL, Brunstrom J, Tsai LH (2003) Layering defect in p35 deficiency is linked to improper neuronal- glial interaction in radial migration. Nat Neurosci 6:1284-1291.

Fleck MW, Hirotsune S, Gambello MJ, Phillips-Tansey E, Suares G, Mervis RF, Wynshaw-Boris A, McBain CJ (2000) Hippocampal abnormalities 
and enhanced excitability in a murine model of human lissencephaly. J Neurosci 20:2439-2450.

Hayashi S, McMahon AP (2002) Efficient recombination in diverse tissues by a tamoxifen-inducible form of Cre: a tool for temporally regulated gene activation/inactivation in the mouse. Dev Biol 244:305-318.

Hirotsune S, Fleck MW, Gambello MJ, Bix GJ, Chen A, Clark GD, Ledbetter DH, McBain CJ, Wynshaw-Boris A (1998) Graded reduction of Pafahlb1 (Lis1) activity results in neuronal migration defects and early embryonic lethality. Nat Genet 19:333-339.

Li J, Lee WL, Cooper JA (2005) NudEL targets dynein to microtubule ends through LIS1. Nat Cell Biol 7:686-690.

Lo Nigro C, Chong CS, Smith AC, Dobyns WB, Carrozzo R, Ledbetter DH (1997) Point mutations and an intragenic deletion in LIS1, the lissencephaly causative gene in isolated lissencephaly sequence and Miller-Dieker syndrome. Hum Mol Genet 6:157-164.

McManus MF, Nasrallah IM, Pancoast MM, Wynshaw-Boris A, Golden JA (2004) Lis1 is necessary for normal non-radial migration of inhibitory interneurons. Am J Pathol 165:775-784.

Mori D, Yano Y, Toyo-oka K, Yoshida N, Yamada M, Muramatsu M, Zhang D, Saya H, Toyoshima YY, Kinoshita K, Wynshaw-Boris A, Hirotsune S (2007) NDEL1 phosphorylation by Aurora-A kinase is essential for centrosomal maturation, separation, and TACC 3 recruitment. Mol Cell Biol 27:352-367.

Mori D, Yamada M, Mimori-Kiyosue Y, Shirai Y, Suzuki A, Ohno S, Saya H, Wynshaw-Boris A, Hirotsune S (2009) An essential role of the aPKCAurora A-NDEL1 pathway on neurite elongation via modulation of microtubule dynamics. Nat Cell Biol 11:1057-1068.

Nadarajah B, Parnavelas JG (2002) Modes of neuronal migration in the developing cerebral cortex. Nat Rev Neurosci 3:423-432.

Nadarajah B, Brunstrom JE, Grutzendler J, Wong RO, Pearlman AL (2001) Two modes of radial migration in early development of the cerebral cortex. Nat Neurosci 4:143-150.

Nadarajah B, Alifragis P, Wong RO, Parnavelas JG (2003) Neuronal migration in the developing cerebral cortex: observations based on real-time imaging. Cereb Cortex 13:607-611.

Nasrallah IM, McManus MF, Pancoast MM, Wynshaw-Boris A, Golden JA (2006) Analysis of non-radial interneuron migration dynamics and its disruption in Lis1 + / - mice. J Comp Neurol 496:847-858.

Niethammer M, Smith DS, Ayala R, Peng J, Ko J, Lee MS, Morabito M, Tsai LH (2000) NUDEL is a novel Cdk5 substrate that associates with LIS1 and cytoplasmic dynein. Neuron 28:697-711.

Reiner O, Carrozzo R, Shen Y, Wehnert M, Faustinella F, Dobyns WB, Caskey CT, Ledbetter DH (1993) Isolation of a Miller-Dieker lissencephaly gene containing $\mathrm{G}$ protein beta-subunit-like repeats. Nature 364:717721.

Reynolds BA, Weiss S (1996) Clonal and population analysis demonstrate that an EGF-responsive mammalian embryonic CNS precursor is a stem cell. Dev Biol 175:1-13.

Sasaki S, Shionoya A, Ishida M, Gambello MJ, Yingling J, Wynshaw-Boris A, Hirotsune S (2000) A LIS1/NUDEL/cytoplasmic dynein heavy chain complex in the developing and adult nervous system. Neuron 28:681696.

Sasaki S, Mori D, Toyo-oka K, Chen A, Garrett-Beal L, Muramatsu M,
Miyagawa S, Hiraiwa N, Yoshiki A, Wynshaw-Boris A, Hirotsune S (2005) Complete loss of Ndell results in neuronal migration defects and early embryonic lethality. Mol Cell Biol 25:7812-7827.

Schaar BT, McConnell SK (2005) Cytoskeletal coordination during neuronal migration. Proc Natl Acad Sci U S A 102:13652-13657.

Schmid RS, Shelton S, Stanco A, Yokota Y, Kreidberg JA, Anton ES (2004) alpha3beta1 integrin modulates neuronal migration and placement during early stages of cerebral cortical development. Development 131: 6023-6031.

Shim SY, Samuels BA, Wang J, Neumayer G, Belzil C, Ayala R, Shi Y, Shi Y, Tsai LH, Nguyen MD (2008) Ndell controls the dynein-mediated transport of vimentin during neurite outgrowth. J Biol Chem 283:1223212240.

Shu T, Ayala R, Nguyen MD, Xie Z, Gleeson JG, Tsai LH (2004) Ndel1 operates in a common pathway with LIS1 and cytoplasmic dynein to regulate cortical neuronal positioning. Neuron 44:263-277.

Tanaka T, Serneo FF, Higgins C, Gambello MJ, Wynshaw-Boris A, Gleeson JG (2004) Lis1 and doublecortin function with dynein to mediate coupling of the nucleus to the centrosome in neuronal migration. J Cell Biol 165:709-721.

Toyo-oka K, Shionoya A, Gambello MJ, Cardoso C, Leventer R, Ward HL, Ayala R, Tsai LH, Dobyns W, Ledbetter D, Hirotsune S, Wynshaw-Boris A (2003) 14-3-3epsilon is important for neuronal migration by binding to NUDEL: a molecular explanation for Miller-Dieker syndrome. Nat Genet 34:274-285.

Toyo-Oka K, Sasaki S, Yano Y, Mori D, Kobayashi T, Toyoshima YY, Tokuoka SM, Ishii S, Shimizu T, Muramatsu M, Hiraiwa N, Yoshiki A, Wynshaw-Boris A, Hirotsune S (2005) Recruitment of katanin p60 by phosphorylated NDEL1, an LIS1 interacting protein, is essential for mitotic cell division and neuronal migration. Hum Mol Genet 14:31133128.

Tsai JW, Chen Y, Kriegstein AR, Vallee RB (2005) LIS1 RNA interference blocks neural stem cell division, morphogenesis, and motility at multiple stages. J Cell Biol 170:935-945.

Tsai JW, Bremner KH, Vallee RB (2007) Dual subcellular roles for LIS1 and dynein in radial neuronal migration in live brain tissue. Nat Neurosci 10:970-979.

Vallee RB, Tsai JW (2006) The cellular roles of the lissencephaly gene LIS1, and what they tell us about brain development. Genes Dev 20:1384-1393.

Wynshaw-Boris A (2007) Lissencephaly and LIS1: insights into the molecular mechanisms of neuronal migration and development. Clin Genet 72:296-304.

Yamada M, Toba S, Yoshida Y, Haratani K, Mori D, Yano Y, Mimori-Kiyosue Y, Nakamura T, Ito K, Fushiki S, Setou M, Wynshaw-Boris A, Torisawa T, Toyoshima YY, Hirotsune S (2008) LIS1 and NDEL1 coordinate the plusend-directed transport of cytoplasmic dynein. EMBO J 27:2471-2483.

Yingling J, Youn YH, Darling D, Toyo-Oka K, Pramparo T, Hirotsune S, Wynshaw-Boris A (2008) Neuroepithelial stem cell proliferation requires LIS1 for precise spindle orientation and symmetric division. Cell 132:474-486.

Zhuo L, Theis M, Alvarez-Maya I, Brenner M, Willecke K, Messing A (2001) hGFAP-Cre transgenic mice for manipulation of glial and neuronal function in vivo. Genesis 31:85-94. 